\title{
Histopathology of hepatocellular carcinoma - when and what
}

\author{
Doreen Maria Gisder, Andrea Tannapfel, Iris Tischoff \\ Institut der Pathologie, Ruhr Universität Bochum, Bochum 44789, Germany.
}

Correspondence to: Dr. Doreen Maria Gisder, Institut der Pathologie, Ruhr Universität Bochum, Bürkle de la Camp-Platz 1, Bochum 44789, Germany. E-mail: doreen-maria.gisder@pathologie-bochum.de

How to cite this article: Gisder DM, Tannapfel A, Tischoff I. Histopathology of hepatocellular carcinoma - when and what. Hepatoma Res 2022;8:4. https://dx.doi.org/10.20517/2394-5079.2021.106

Received: 9 Aug 2021 First Decision: 11 Oct 2021 Revised: 29 Oct 2021 Accepted: 6 Dec 2021 Published: 7 Jan 2022

Academic Editor: Giuliano Ramadori Copy Editor: Yue-Yue Zhang Production Editor: Yue-Yue Zhang

\begin{abstract}
When do you need to take biopsies of the liver, and what information will you get is the topic of this review on hepatocellular carcinoma (HCC). If, clinically, the differential diagnosis of HCC after imaging is suggested, a biopsy has become obligatory as a diagnostic confirmation of HCC in the non-cirrhotic liver prior to definitive therapeutic interventions, as well as in a palliative therapy concept. In the case of hepatic lesions with an uncharacteristic contrast uptake, a biopsy should be performed immediately to confirm the diagnosis of HCC. After diagnosing $\mathrm{HCC}$, a treatment strategy is evaluated. Further, the biopsy, or in case of surgical treatment, the resected tissue, shows us the different subtypes of HCC, with the steatohepatitic subtype being the most common and the lymphocyte-rich subtype being the least common. Further, the histological grade of HCC is determined according to the grading system of the WHO or the Edmonson and Steiner System. Through biopsies, HCC can be differentiated from intrahepatic cholangiocarcinoma or combined hepatocellular-cholangiocarcinoma or metastases of other malignant tumors, especially metastases of the gastrointestinal tract. In summary, biopsies are fundamental in the diagnosis of HCC.
\end{abstract}

Keywords: Hepatocellular carcinoma, biopsies, histology

\section{INTRODUCTION, DEFINITION, AND EPIDEMIOLOGY}

Hepatocellular carcinoma (HCC) is a primary liver tumor with hepatocytic differentiation. HCC arises from the hepatocyte in various stages of differentiation. The incidence of HCC in Europe and the United States 
will continue to increase with the progression of hepatitis $\mathrm{C}$, nonalcoholic steatohepatitis, and obesity with diabetes mellitus and metabolic syndrome ${ }^{[1,2]}$. In Germany, around 9000 new cases of HCC occur each year, with an incidence of 6.4/100,000 for men and 1.5/100,000 for women ${ }^{[3-5]}$. Clinically, the tumor marker for HCC is alpha-fetoprotein (AFP). However, it has significant limitations in terms of sensitivity (39\% to $64 \%$ ) and specificity (76\% to $91 \%$ ). AFP levels greater than $20 \mathrm{ng} / \mathrm{mL}$, as well as lower but slowly increasing levels, are a serious indication for HCC. Levels greater than $200 \mathrm{ng} / \mathrm{mL}$ are highly suspicious for diagnosis of HCC if positive on imaging. However, AFP levels do not correlate very closely with the size of the HCC. Other specific and sensitive HCC markers have been searched for decades. Several alternative markers have been investigated, for example, des-gamma-carboxyprothrombin, glypican-3, AFP fractions, but they are not yet used in clinical practice ${ }^{[6-8]}$. In almost all cases, prior to therapy, a precise histopathological diagnosis is mandatory, especially in tumors without cirrhosis. The histological HCC subtyping should be done according to the latest World Health Organization (WHO) classification. Next to tumor typing (i.e., HCC determination, subtyping, and ruling out intrahepatic cholangiocarcinoma), the grade of tumor differentiation ("grading") is necessary. There are three grading systems for the HCC. The HCC-specific grading of Edmondson and Steiner described by Edmondson and Steiner ${ }^{[0]}$, the grading according to Nzeako et al. ${ }^{[10,11]}$, and the International Union Against Cancer (UICC) grading ${ }^{[12]}$. The general UICC grading is not entity-specific, is less detailed, and is explicitly rarely applied in the context of HCC. Grading, according to Edmondson and Steiner, is recommended by UICC in $\mathrm{HCC}^{[12]}$. Nzeako et al. ${ }^{[1,11]}$ grading is more commonly used in the European and American regions. This grading is based purely on nuclear features. Staging of HCC must be performed according to the current Malignant Tumours (TNM) classification $^{[13]}$. Another point of histopathological diagnosis is the early detection of precancerous lesions in cirrhotic and non-cirrhotic liver.

\section{WHEN-BIOPSY?}

Due to the increase of HCC to the 5th most common cancer in Europe and worldwide, there has been an update of the guidelines on treatment strategies, especially concerning when to take biopsies ${ }^{[1,15]}$. In 2013, it was recommended that a biopsy should only be obtained if it has a therapeutic consequence. In 2021, biopsy has been strengthened as an important diagnostic measure. The diagnostic algorithm has changed so that lesions greater than $1 \mathrm{~cm}$ in size should now receive an imaging examination rather than only lesions greater than $2 \mathrm{~cm}$. If a lesion shows the characteristic contrast enhancement, a curative or palliative therapy concept can be initiated depending on the size and extension of the HCC. Interestingly, the detection rate of small lesions has increased in recent years, leading to new therapeutic strategies ${ }^{[16-18]}$. In particular, imageguided tumor ablation for early-stage HCC gained attention as a therapeutic strategy. This therapy is a nonsurgical treatment that provides local tumor control, and the patients have more favorable survival benefits. Before ablation, a biopsy is taken for the histopathological examination to confirm the diagnose of HCC. The biopsy should be taken prior to ablation to reduce necrosis in the tissue to be examined ${ }^{[19-21]}$. All in all, biopsy has become obligatory as a diagnostic confirmation of HCC in the non-cirrhotic liver before definitive therapeutic interventions, as well as in a palliative therapy concept. In the case of hepatic lesions with an uncharacteristic contrast uptake, a biopsy should be performed immediately to confirm the diagnosis of HCC. Further, if a palliative therapy concept is considered, a biopsy should be performed to exclude other differential diagnoses and to confirm $\mathrm{HCC}^{[22]}$. In the circumstance of a curative concept, further imaging should be performed. If this second imaging continues to show uncharacteristic contrast enhancement, a biopsy is an obligatory procedure. The interpretation of the biopsy and the diagnosis of HCC can be made in many cases by conventional histology. Depending on the histopathological appearance, further examinations, in particular immunohistochemistry, can be used to confirm the diagnosis ${ }^{[23-25]}$. 
For an adequate histopathological interpretation of the biopsy, the specimen must be taken from the lesion and must be of sufficient size ${ }^{[26]}$. To obtain a relevant sample of a focal liver lesion, image guidance, with either real-time ultrasound, computer tomography, or magnetic resonance imaging, is necessary to place the needle accurately within the lesion ${ }^{[27]}$. Further studies claim that a longer sample size increases the chance of a possible adequate histopathological interpretation ${ }^{[28-30]}$. The guidelines on the use of liver biopsies in clinical practice from the British Society of Gastroenterology, the Royal College of Radiologists, and the Royal College of Pathology recommend a sample that should be at least $20 \mathrm{~mm}^{[2,3,1]}$. In general, only one pass is required if an adequate sample is obtained. Nevertheless, studies have demonstrated a more accurate diagnose with an increased number of needle passes. Three or more passes should not be performed as this significantly increases the risk of complications and morbidity ${ }^{[32-34]}$. The current state of knowledge doesn't specify if a lesion biopsy should be taken through adjacent liver tissue to minimize the risk of so-called "punch channel tumor spreading". How biopsies should be taken depends on the case and the localization of the lesion, and they should be taken with the lowest impact on the liver and patient. In consensus with our hepatologists, a biopsy should be taken as directly as possible. The complication rate of biopsy of HCC is low and includes the risk of hemorrhage and so-called "punch channel tumor spreading". Minor bleeding requires no treatment and occurs in approximately $3 \%-4 \%$ of cases. Bleeding requiring transfusion is rare $(0.5 \%)^{[35]}$. Meta-analyses have shown that "punch channel tumor spreading" is also rare $(2.7 \%)$. They typically occur late, approximately after a mean of 17 months, and are usually well treatable and have no negative impact on survival as well as on the success of therapeutic measures ${ }^{[36-38]}$. Another indication for a biopsy can be a portal vein thrombosis. Portal vein thrombosis may be either portal vein tumor thrombosis or benign portal vein thrombosis. It is important to distinguish between them as they are relevant to patient outcome and therapeutic strategies ${ }^{[39-41]}$. In particular, when HCC occurs in a cirrhotic liver, the differentiation can be difficult, as benign portal vein thrombosis often occurs in cirrhotic livers. The first diagnostic procedure for differentiation is imaging ${ }^{[42-44]}$. However, if imaging does not fulfill the characteristic criteria of portal vein tumor thrombosis or benign portal vein thrombosis, an ultrasoundguided fine-needle aspiration biopsy can be performed for differentiation ${ }^{[44,45]}$.

In any case, a malignant liver tumor cannot be diagnosed without a histological examination since the classification of malignant liver tumors is based on histological criteria. Overall, histopathology is the basis of HCC diagnosis and its differential diagnoses. If any concerns occur concerning a clinical diagnose of HCC, a biopsy should be considered. The criteria for the current diagnosis of malignant liver tumors are summarized in the 5th edition of the WHO Classification of Tumors of the Digestive Tract ${ }^{[46-48]}$. If the patient's history does not include information regarding the underlying liver disease, an additional biopsy of liver tissue could be obtained to evaluate whether fibrosis or cirrhosis is presented. This information is essential for further therapeutical decision-making and patient outcome. In this case, the Royal College of Pathologists updated guidelines suggesting a minimum adequacy requirement for samples being at least $10 \mathrm{~mm}$ long and containing six portal tracts. New studies underline that a biopsy including fewer than 11 portal tracts per tissue section might underestimate the degree of fibrosis and inflammation ${ }^{[3,49]}$.

\section{WHAT YOU GET AFTER BIOPSY OR RESECTION}

Not only the histological subtype, the primary resectability or the degree of liver cirrhosis are important factors to evaluate the prognosis and outcome for the patient. It is further important to look at the macroscopic appearance of the tumor. HCCs occur as solid, green to yellow nodes of various sizes in the liver. The green to yellow color is caused by the bilious imbibition and the fat content of the tumor. Compared to the non-neoplastic liver tissue and especially in cirrhotic liver, HCCs appear as a soft tumor. In cirrhotic livers, they have additionally a pseudocapsule. Little has been reported on the role of macroscopic classification of HCC and the prognostic role. However, the macroscopic classification of HCC 
might have a strong correlation with long-term prognosis after hepatectomy ${ }^{[50]}$. Historically, four types of HCC were described by Eggel in 1901. He divided the neoplasms into the expansive (nodule), infiltrative, mixed (expansive and infiltrative), and diffuse types. The prevalence among cases are: $20 \%$ nodule, 33\% infiltrative, $42 \%$ mixed, and $5 \%$ diffuse. The data published by Eggel are based on HCCs arising in cirrhosis $^{[51]}$. Nowadays, the exclusive morphological classification by Eggel has been mostly left behind since it does not allow conclusions to be made concerning the etiology, clinical course, or prognosis ${ }^{[52,53]}$. Besides this, the macroscopic description of the HCC still has an important clinical impact when it comes to describing the size of the primary tumor, the size of additional tumor nodes with correlation to the primary tumor, and tumor vessel invasion. For example, for tumor size, there was a significant difference between tumors smaller than $5 \mathrm{~cm}$ and those larger than this. In tumors measuring less than $5 \mathrm{~cm}$, intrahepatic metastasis, portal vein involvement, and lymphogenous and hematogenous metastasis were not common. However, these frequencies became significantly higher if the tumor exceeded $5 \mathrm{~cm}$. Comparing the percentages of tumors less than $5 \mathrm{~cm}$ and greater than $5 \mathrm{~cm}$, intrahepatic metastases were observed in $60.6 \%$ and $95.7 \%$, portal vein involvement in $40 \%$ and $74.5 \%$, lymph node metastases in $0 \%$ and $40.4 \%$, and hematogenous metastases in $6.7 \%$ and $51.1 \%$, respectively ${ }^{[53]}$. Further, the macroscopic description of whether there is vessel invasion is relevant to TNM. HCCs often appear hypervascular and have close contact with the vessels [Figure 1A-D] ${ }^{[54,55]}$. If a second tumor occurs in the liver, the distance to the first and biggest one must be described. Additionally, it must be ensured that they were separated by non-neoplastic liver tissue. Whether this second tumor is an intrahepatic metastasis or a second synchronic or heterochinic tumor is still discussed ${ }^{[56-59]}$. Tumors arising within a radius of less than $2 \mathrm{~cm}$ to the primary tumor, and if they are smaller than the primary tumor, are called satellite nodules. Another special anatomic appearance of HCC is the pedunculated HCC. It is a rare subtype, which can be further categorized by its presence or absence of a pedicle attaching it to the liver ${ }^{[60-62]}$. Especially the macroscopic described tumor size is relevant for the WHO grading system. This grading system for HCC proposed by the WHO takes not only the tumor size but also the architecture and the extent of cell and nuclear pleomorphism (including sarcomatoid or anaplastic morphology) into account ${ }^{[12,48]}$.

\section{HISTOLOGICAL SUBTYPES}

There are various numbers of different subtypes of HCC. They differ by morphology and/or immunohistochemistry. All different types of HCC show cytological atypia varying from minimal to marked, and the tumor cells show an increased proliferation. Characteristic cellular changes of HCC include bile production, lipofuscin deposits, glycogen accumulation leading to clear cell changes, and fatty changes [Figure 2A-C]. The tumor cells can develop inclusions such as hyaline bodies, Mallory-dense bodies, or pale bodies [Figure 2D]. Further, they have a loss of typical hepatic architecture, such as loss of portal tracts or reduction/loss of the normal reticulin framework. As described in the macroscopic appearance, they show histologically an increased arterialization with sinusoidal capillarization and aberrant arterioles. The capillaries of the tumor are lined by a single layer of endothelium, which differs from non-neoplastic capillaries. The endothelium of the tumor shows an immunohistochemical expression of CD34, factor VIII, and type IV collagen. Electron microscopy shows a basement membrane between tumor cells and endothelial cells.

There are four principal growth patterns of HCCs: trabecular, solid (syn.: compact), pseudoglandular (syn.: pseudocarina), and macrotrabecular [Figure 3A-C]. Half of all resected HCCs have mixed patterns. It is mostly a combination of trabecular plus one or two others. The pathologist may recognize the growth pattern, but it must not be described since it does not have any clinical relevance. However, in a recently published study suggests there might be an association between the macrotrabecular pattern and a worse prognosis. A special pattern is nodule-in-nodule growth. In this case, a nodule of poor differentiation arises 

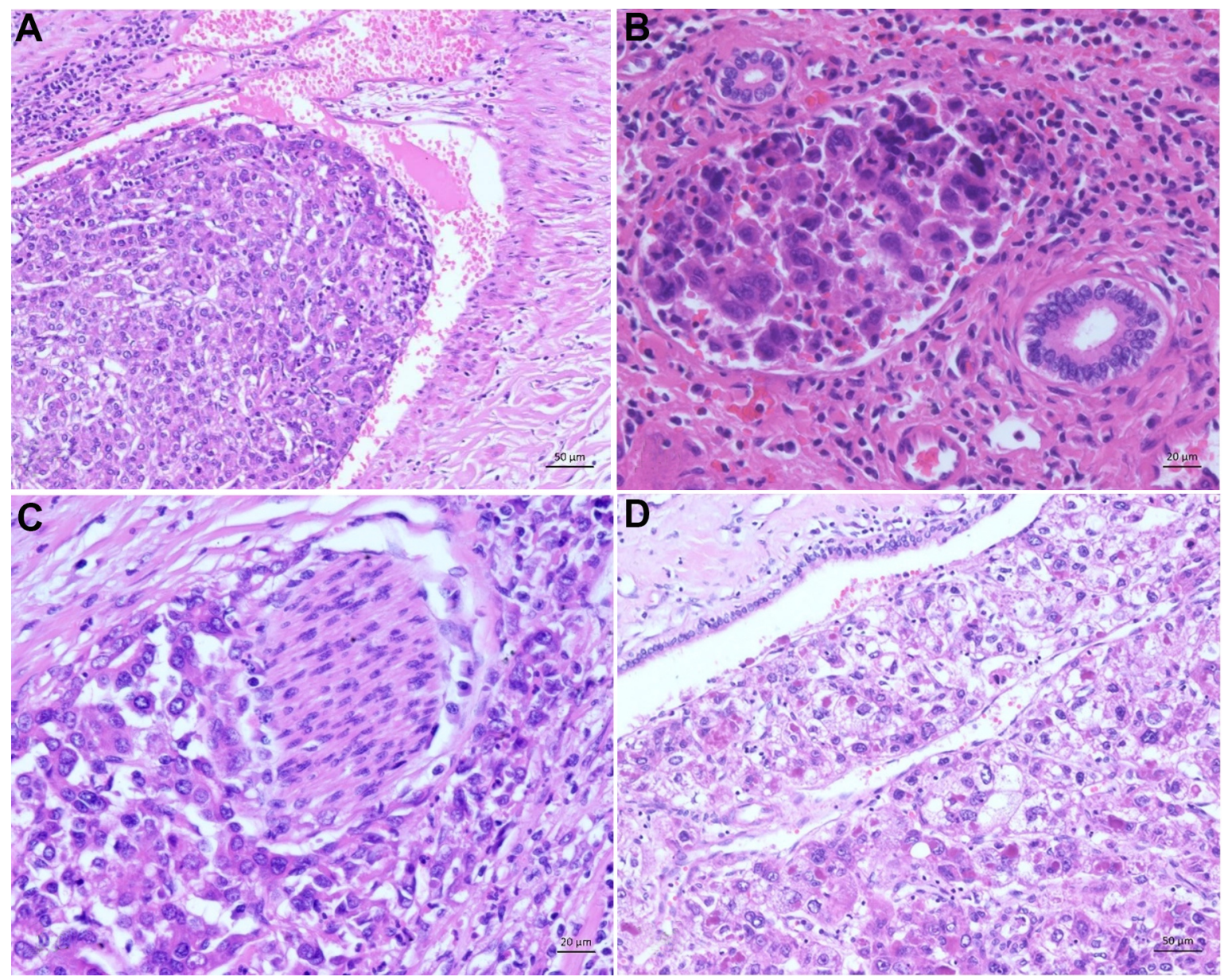

Figure 1. (A) Vascular invasion of hepatocellular carcinoma. (B) Invasion in a small lymph vessel of portal tract of hepatocellular carcinoma. (C) Hepatocellular carcinoma with perineural invasion. (D) Hepatocellular carcinoma invasion in an intrahepatic bile duct.

within an existing $\mathrm{HCC}^{[63]}$.

The histological grading system of the WHO is based on H\&E staining and compares the differentiation of the tumor cell with the benign hepatocytes. The WHO proclaims a three-stage system. There are welldifferentiated (G1), moderately differentiated (G2), and poorly differentiated (G3) HCCs [Table 1, Figure $4 \mathrm{~A}-\mathrm{C}]$. Undifferentiated tumors are excluded from this system because they have no compelling evidence for being either hepatocellular or biliary and are not a grade of HCC [Table 1] ${ }^{[12]}$. Some HCC may have intratumoral heterogeneity concerning the grade. In this case, the predominant grade or a combination of the worst can be reported, due to the fact that the worst grade tends to drive the prognosis. A uniform worldwide used grading system remains to be developed. One example of a currently often used grading system is the Edmonson and Steiner System, which favors a three-tiered grading system [Table 2]. It was developed by Edmonson and Steiner in 1954 and is based on nuclear-cytoplasmic ratio, the grade of acidophilic, chromatin content, the bile production, and the histological architecture ${ }^{[9]}$.

Of the HCCs, 35\% can be further classified into eight distinct subtypes, which will be described below. All subtypes except the fibrolamellar, which only occurs in non-cirrhotic livers, have been described in cirrhotic and non-cirrhotic liver. The most common type is the steatohepatitic $\mathrm{HCC}^{[64,65]}$. 
Table 1. World Health Organization ${ }^{[9]}$

\begin{tabular}{llll}
\hline Grades & Architecture & Cytology & Other features \\
\hline Well differentiated & $\begin{array}{l}\text { Thin trabecular, frequent acinar } \\
\text { structures }\end{array}$ & Minimal atypia & Fatty change is frequent \\
Moderately & $\begin{array}{l}\text { Trabecular (3 or more cells in } \\
\text { thifferentiated }\end{array}$ & $\begin{array}{l}\text { Abundant eosinophilic cytoplasm, round nuclei } \\
\text { with distinct nucleoli }\end{array}$ & $\begin{array}{l}\text { Bile or proteinaceous fluid } \\
\text { within acini }\end{array}$ \\
Poor differentiated & Solid & Moderate to marked pleomorphism & $\begin{array}{l}\text { Absence of sinusoid-like } \\
\text { blood spaces }\end{array}$ \\
Undifferentiated & Solid & Little cytoplasm, spindle, or round-shaped cells & - \\
\hline
\end{tabular}

Table 2. Edmondson and Steiner ${ }^{[9]}$

\begin{tabular}{|c|c|c|c|}
\hline Grades & Architecture & Cytology & Other features \\
\hline I & - & - & $\begin{array}{l}\text { Areas of carcinoma where distinction } \\
\text { from hyperplastic liver is difficult }\end{array}$ \\
\hline II & $\begin{array}{l}\text { Trabecular, frequent acini (lumen varying from } \\
\text { tiny canaliculi to large thyroid-like spaces) }\end{array}$ & $\begin{array}{l}\text { Resemblance to normal hepatic cells; larger } \\
\text { nuclei; abundant acidophilic cytoplasm }\end{array}$ & $\begin{array}{l}\text { Cell borders sharp and clear cut; acini } \\
\text { containing bile or protein precipitate }\end{array}$ \\
\hline III & $\begin{array}{l}\text { Distortion of trabecular structure, acini less } \\
\text { frequent than grade II }\end{array}$ & $\begin{array}{l}\text { Larger, more hyperchromatic nuclei, } \\
\text { granular but less acidophilic cytoplasm }\end{array}$ & $\begin{array}{l}\text { Acini are less frequent; tumor giant } \\
\text { cells may be numerous }\end{array}$ \\
\hline IV & Medullary, less trabeculae, rare acini & $\begin{array}{l}\text { Highly hyperchromatic nuclei, scanty } \\
\text { cytoplasm, with fewer granules }\end{array}$ & $\begin{array}{l}\text { Loss of cell cohesiveness; giant, spindle } \\
\text { or short-plump cells can be found }\end{array}$ \\
\hline
\end{tabular}

Immunohistochemically, HCCs show an antibody reaction against carbamoylphosphat-synthetase-1 (HEP $P A R 1)$. The poorer the degree of differentiation of HCC, the lower the expression of HEP PAR $1^{[66]}$. Further, an expression of CD10, cytokeratin-8, and cytokeratin-18 can be obtained ${ }^{[67]}$. There is no expression of cytokeratin-20 as well as epithelial membrane antigen (EMA). Cytokeratin-7 and -19 usually are not expressed but may be observed in high-grade HCC. AFP expression usually indicates malignancy and can be seen in $50 \%$ of cases. Further, glypican 3 can be used as a diagnostic marker for differentiating between HCC from non-malignant liver lesions. A high glypican 3 positive staining significantly correlates with later tumor stage, higher tumor grade, presence of vascular invasion, shortened overall survival, and shortened disease-free survival. Shafizadeh et al. ${ }^{[68]}$ reported an expression of glypican 3 in 9/16 (56\%) well, 15/18 (83\%) moderately, and 22/24 (89\%) poorly differentiated HCC. A diffuse expression can be seen of the 70 kilodalton heat shock proteins (HSP 70) and glutamine synthetase ${ }^{[68-71]}$. In routine clinical work, immunohistochemistry is of limited value in the differential diagnosis. In most cases, the diagnosis of HCC can be based on the H\&E staining.

\section{Steatohepatitic hepatocellular carcinom}

The steatohepatitic subtype is the most common, with 5\%-20\% prevalence among HCCs. The tumor cells show histological features of steatohepatitis, such as containing fatty vacuoles, an intratumoral stroma reaction, and inflammation. Further, it is often associated with metabolic syndrome and steatohepatitis or even cirrhosis of the liver [Figure $5 \mathrm{~A}-\mathrm{C}]^{[72-75]}$.

\section{Clear cell hepatocellular carcinoma}

With $3 \%-7 \%$ prevalence, it is the second most common subtype. Of the tumor cells, $80 \%$ show a clear cell morphology with a light cytoplasm and minor nuclear atypia. The "brightness" of the cells occurs because the tumor cells accumulate glycogen [Figure $6 \mathrm{~A}-\mathrm{C}]^{[76-78]}$.

\section{Macrotrabecular (massive) hepatocellular carcinoma}

To classify this subtype, there must be at least $50 \%$ of a macrotrabecular growth pattern ${ }^{[79,80]}$. The tumor occurs in $5 \%$ of the cases and is associated with a worse prognosis. Clinically, a high serum 


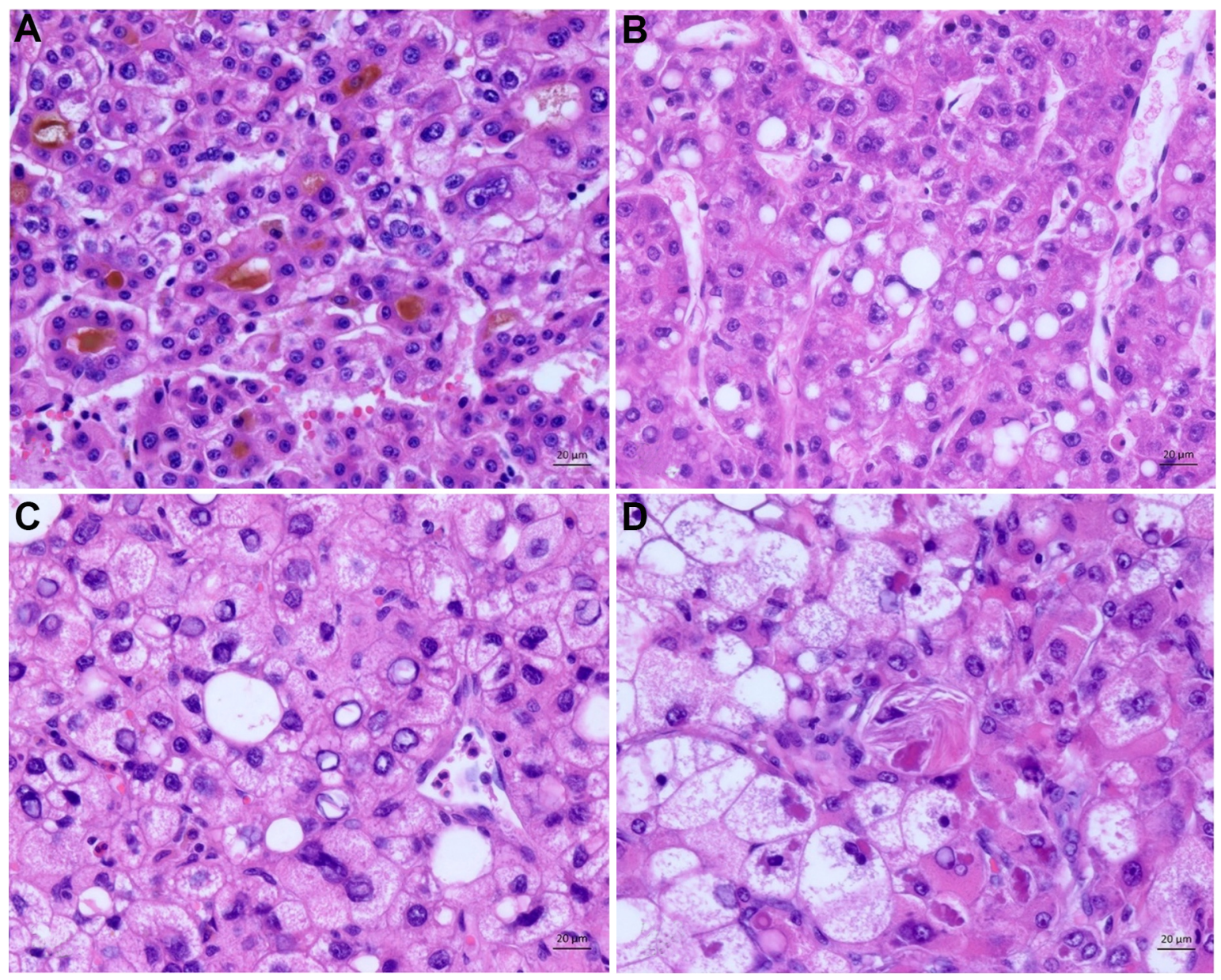

Figure 2. Characteristic cellular changes in hepatocellular carcinoma. (A) Tumor cells with bile production. (B) Fatty changes with intracytoplasmic accumulation of lipids. (C) Glycogenated nuclei. (D) Hyaline bodies (Mallory Denk bodies): eosinophilic cytoplasmic inclusions.
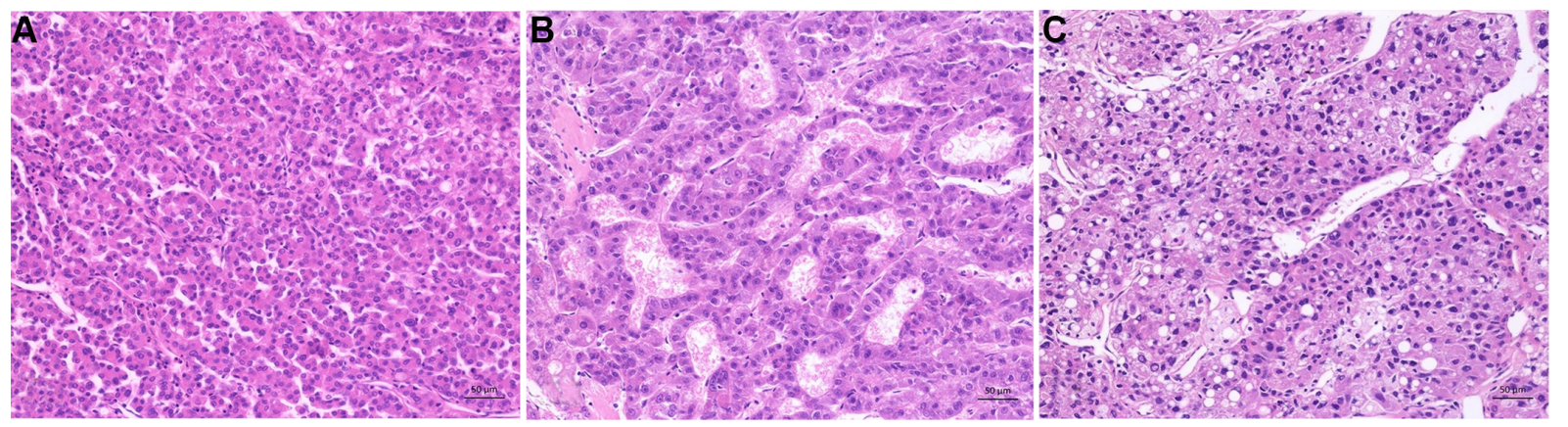

Figure 3. Histological growth pattern. (A) Trabecular pattern: thin tumor trabeculaes with not more than ten cells in thickness. (B) Pseudoglandular pattern: glandular-like or acinus-like structures with minimal atypia. (C) Macrotrabecular Pattern: trabecular structures with more than 10 cells in thickness, increased nuclear:cytoplasma ratio.

AFP is seen [Figure $3 C]^{[81]}$. 

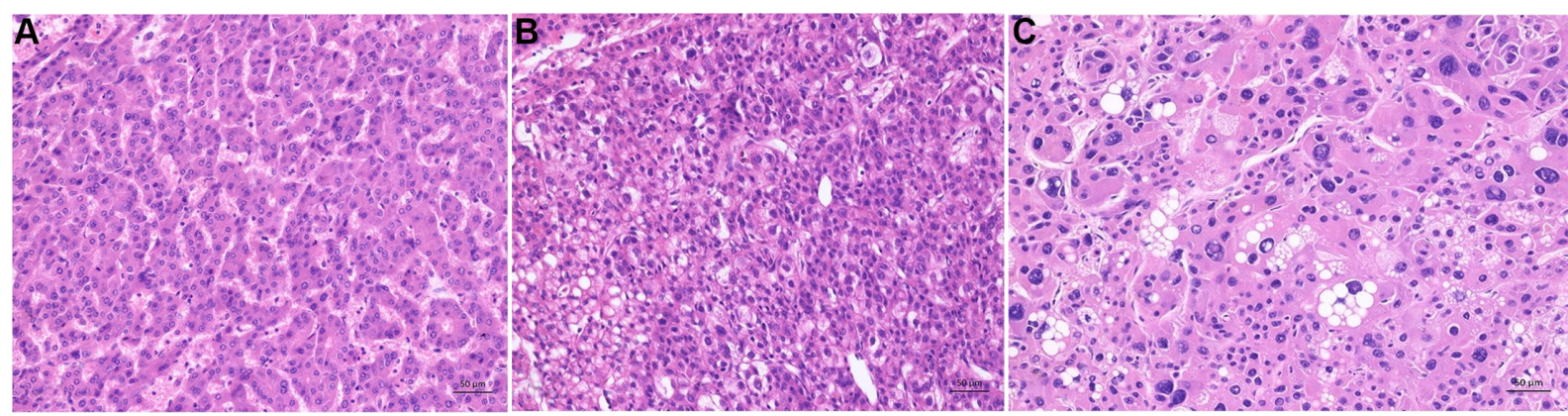

Figure 4. Histological grading of hepatocellular carcinoma according to World Health Organization. (A) Well differentiated hepatocellular carcinoma: thin trabecular structures and minimal atypia of tumor cells resembling mature hepatocytes. (B) Moderately differentiated hepatocellular carcinoma: trabecular pattern with at least 3 cells in thickness, moderate nuclear atypia with increased nuclear:cytoplasma ratio, microvesicular fatty changes (lower left). (C) Poorly differentiated hepatocellular carcinoma: marked pleomorphic tumor cells with fatty changes, prominent nucleoli und anaplastic giant cells.
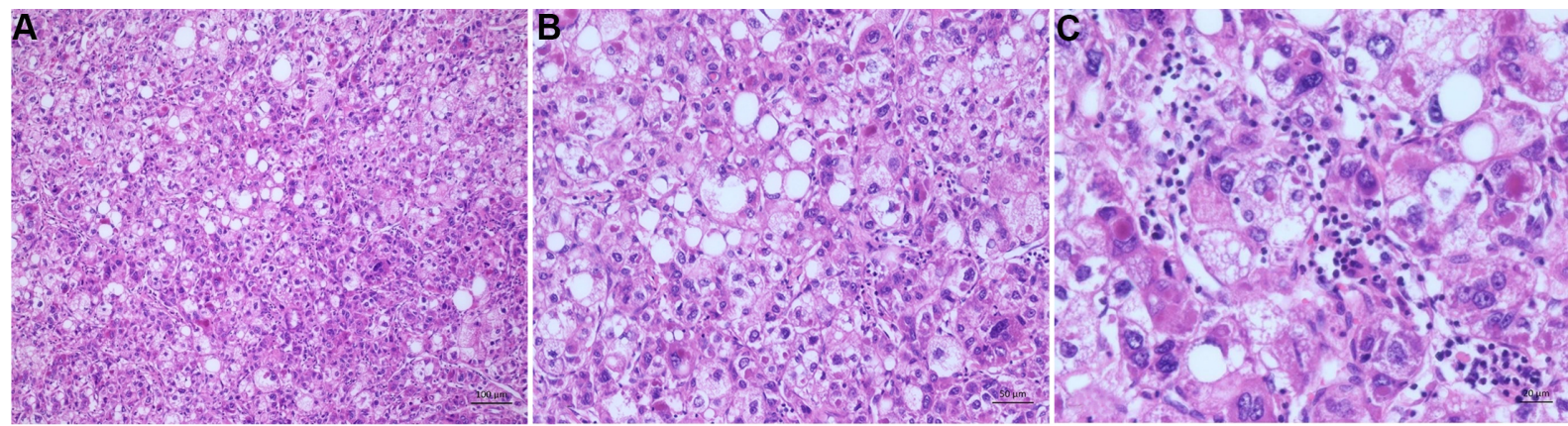

Figure 5. Steatohepatitic subtype. (A) Overview of the steatohepatitic tumor. The tumor cells show histological features of steatohepatitis by containing fatty vacuoles. Further inflammation and an intratumoral stroma reaction is seen. (B) Higher magnification of the tumor. Tumor shows features of steatohepatitis tumor cells with fatty vacuoles and tumor cell ballooning. (C) The tumors characteristic intratumoral inflammation and hyaline bodies (Mallory Denk bodies) are seen here.
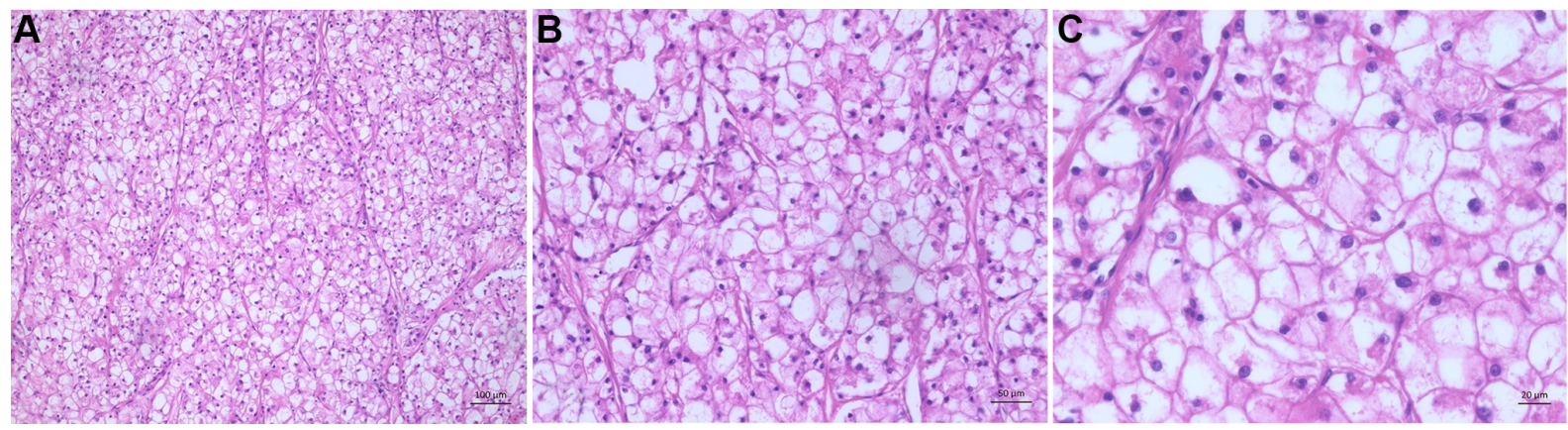

Figure 6. Clear cell subtype. (A) Overview of a clear cell subtype. (B) Tumor trabeculaes with clear cell cytoplasm of tumor cells accumulating glycogen. (C) The tumor cells show a clear cell morphology with a light cytoplasm and minor nuclear atypia.

\section{Scirrhous hepatocellular carcinoma}

Four percent of all HCCs show a scirrhous subtype. This tumor subtype shows dense intratumoral fibrosis of greater than 50\%, which arouses especially in association with the sinusoidal capillarization leading to an atrophy of the tumor trabecular ${ }^{[6,82-84]}$. After chemotherapy or radiation of HCC, the tumor may mimic this subtype. Clinically, this subtype mimics a cholangiocarcinoma on imaging [Figure $7 \mathrm{~B}]^{[6,82,85]}$. 

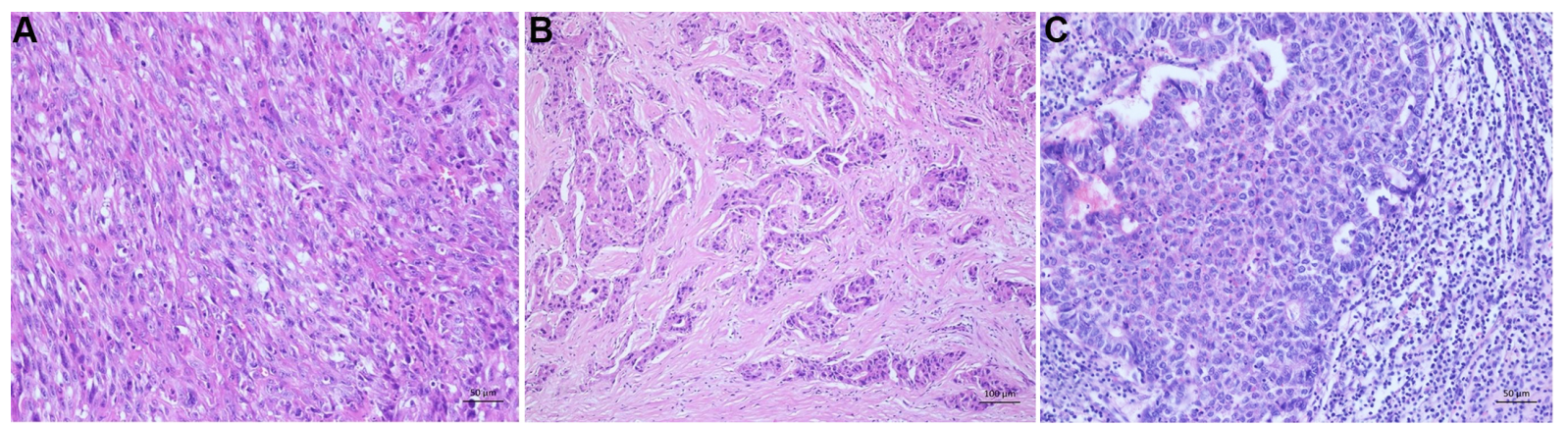

Figure 7. Rare histological subtypes. (A) Sarcomatoid subtype: poorly differentiated HCC with spindle cell morphology resembling sarcoma. (B) Scirrhous subtype: dense intratumoral fibrosis. (C) Neutrophil-rich subtype: poorly differentiated hepatocellular carinoma with numerous intratumoral neutrophils.

\section{Chromophobe hepatocellular carcinoma}

Three percent of the subtypes show a light cytoplasm with outlined cell borders. The tumor nuclei are mainly bland. However, focal areas have striking nuclear atypia, such as two nuclei within one tumor cell. Further, giant cells can be found.

\section{Fibrolamellar hepatocellular carcinoma}

Of all subtypes, $0.5 \%-1 \%$ are fibrolamellar HCCs. Compared to the other subtypes, they often occur in young patients with a median age of 25 years and only occur in non-cirrhotic livers ${ }^{[86-88]}$. So far, no association with chronic liver disease or specific risk factors has been described ${ }^{[89-91]}$. Due to their macroscopic appearance with a central scar and the fact that they are more common in women, they can be misdiagnosed as focal nodular hyperplasia ${ }^{[8,92,93]}$. The tumor cells are large and eosinophilic with prominent nuclei. Another characteristic for diagnosing this subtype is dense intratumoral fibrosis consisting of acellular collagen and pale bodies. The pale bodies are characteristic but not specific, and occur in the classic HCC as well ${ }^{[94]}$ [Figure 8]. In some cases, glandular tumor cell configurations occur, which may lead to the misdiagnosis of combined hepatocellular cholangiocarcinoma [Figure 9] ${ }^{[80]}$.

\section{Neutrophil-rich hepatocellular carcinoma}

This tumor has an incidence of less than $1 \%$ and mainly occurs in older individuals. It shows a histomorphologically significant intratumoral neutrophil-rich inflammation and can have sarcomatoid areas (for an illustration of sarcomatoid morphology refer to Figure 7A). The tumor's key molecular finding is the production of granulocyte colony-stimulating factor, leading to dense areas of infiltrates with neutrophils. Further, some clinical findings, such as elevated leukocyte counts, C-reactive protein, and IL-6, support the diagnosis of a neutrophil-rich HCC [Figure 7C] $]^{[64,95]}$.

\section{Lymphocyte-rich hepatocellular carcinoma}

To diagnose this rare tumor, there must be more lymphocytes than tumor cells in most fields of the H\&E staining. Characteristically, the cords of tumor cells lie in a dense lymphoid stroma. An association with Epstein-Barr virus has been frequently described, but new evidence shows no Epstein-Barr virus relationship, and most cases are negative for Epstein-Barr virus ${ }^{[95]}$.

\section{HISTOLOGICAL DIFFERENTIAL DIAGNOSIS}

Histologically, HCC must be differentiated from combined hepatocellular-cholangiocarcinoma [Figure 9A-C], intrahepatic cholangiocarcinoma [Figure 10A-C], and metastases of other malignant tumors especially hepatoid adenocarcinoma, neuroendocrine tumors, non-keratinizing squamous carcinomas, 

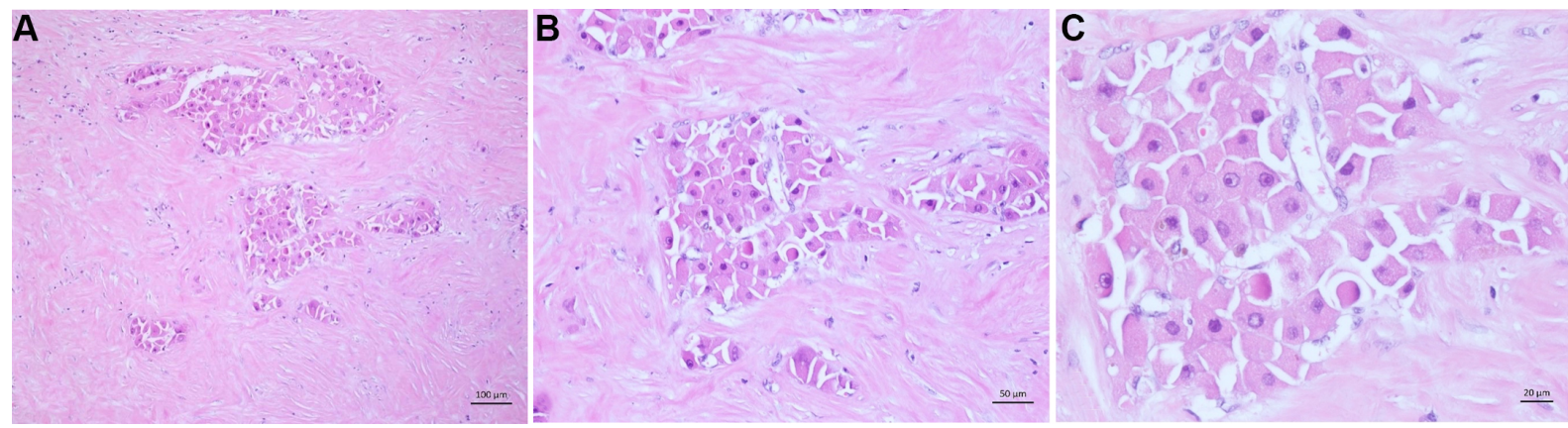

Figure 8. Fibrolamellar subtype. (A) Overview of a fibrolamellar subtype. Scattered tumor cells with eosinophilic cytoplasm in a dense intratumoral fibrosis. (B) The dense intratumoral fibrosis consists of acellular collagen. Some tumor cells contain pale bodies. (C) The tumor cells are large and eosinophilic with prominent nuclei and some tumor cells contain pale bodies.
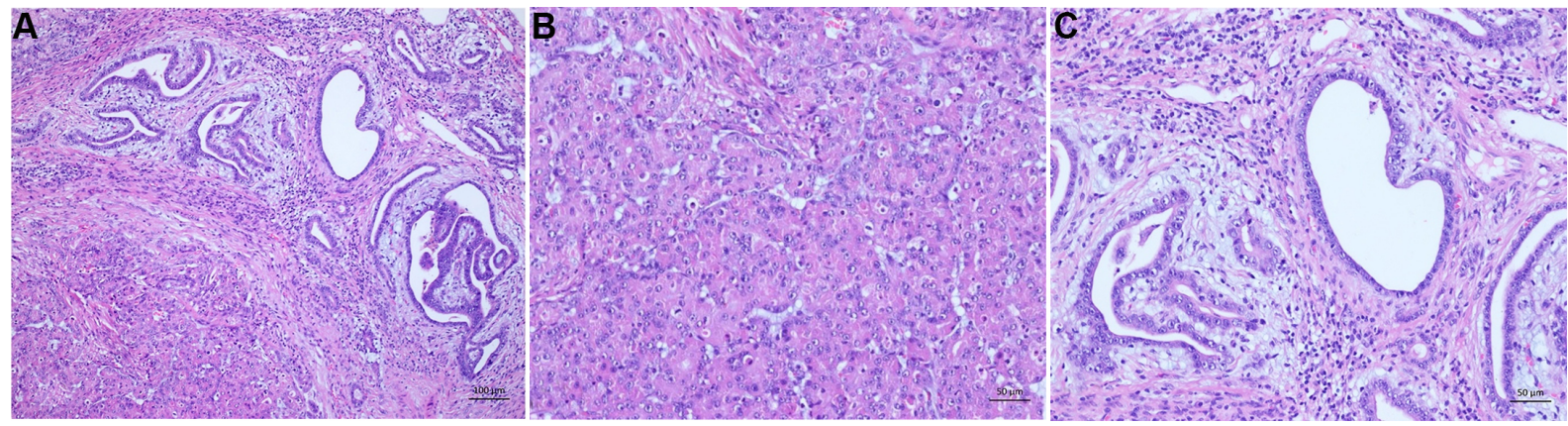

Figure 9. Combined hepatocellular-cholangiocarcinoma. (A) Typical form with moderately differentiated hepatocellular carcinoma (lower left) and well differentiated cholangiocarcinoma (upper right). Between both tumor components a fibrotic border is seen. (B) Hepatocellular carcinoma - component with trabecular pattern and moderate atypia. (C) Cholangiocarcinoma -component with tubular structures and mild atypia.
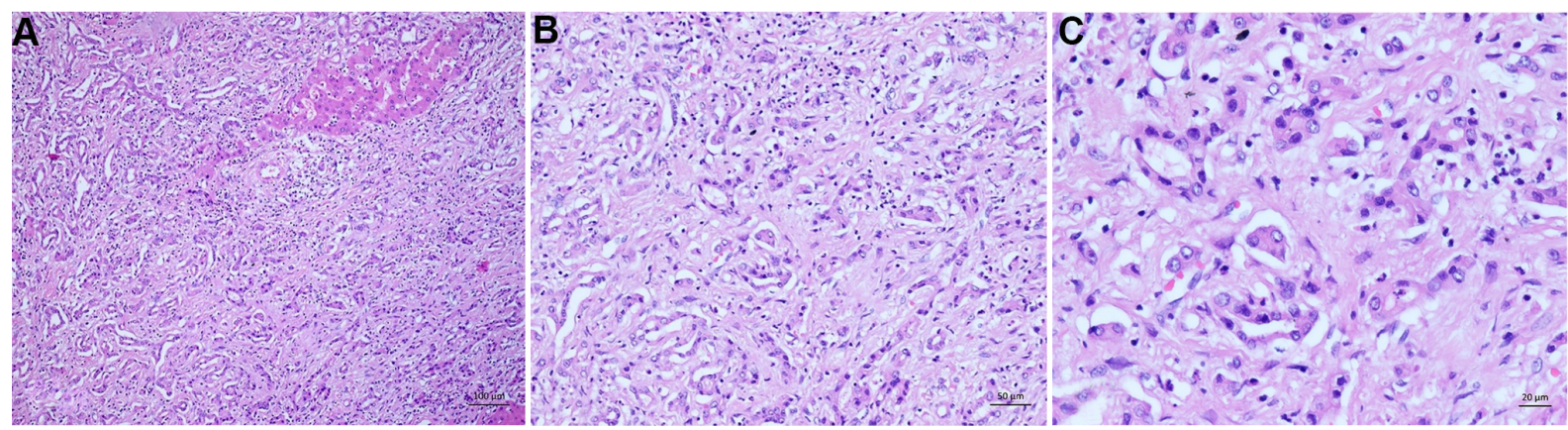

Figure 10. Intrahepatic cholangiocarcinoma. (A) Overview of a moderately differentiated adenocarcinoma with tubular pattern infiltrating a dense fibrous stroma. (B) Infiltrative irregular glands with a prominent fibrodesmoplastic stromal reaction. (C) Higher magnification of the tumor showing the moderately pleomorphic tumor cells with eosinophilic cytoplasm.

urothelial carcinomas, or amelanotic melanomas [Figure 11A-E] ${ }^{[12]}$. The tumor microenvironment is of limited value in the differential diagnosis of HCC. In contrast to intrahepatic cholangiocarcinoma, the tumor surrounding stroma is rare and mostly absent. However, if cirrhosis exists, the pre-test probability increases in favor of a primary malignant liver tumor (e.g., HCC or intrahepatic cholangiocarcinoma). Metastases from distant organs are rarer events in a cirrhotic liver. In certain circumstances, such as a cancer of unknown primary origin with poor differentiation, immunohistochemistry could help to identify 

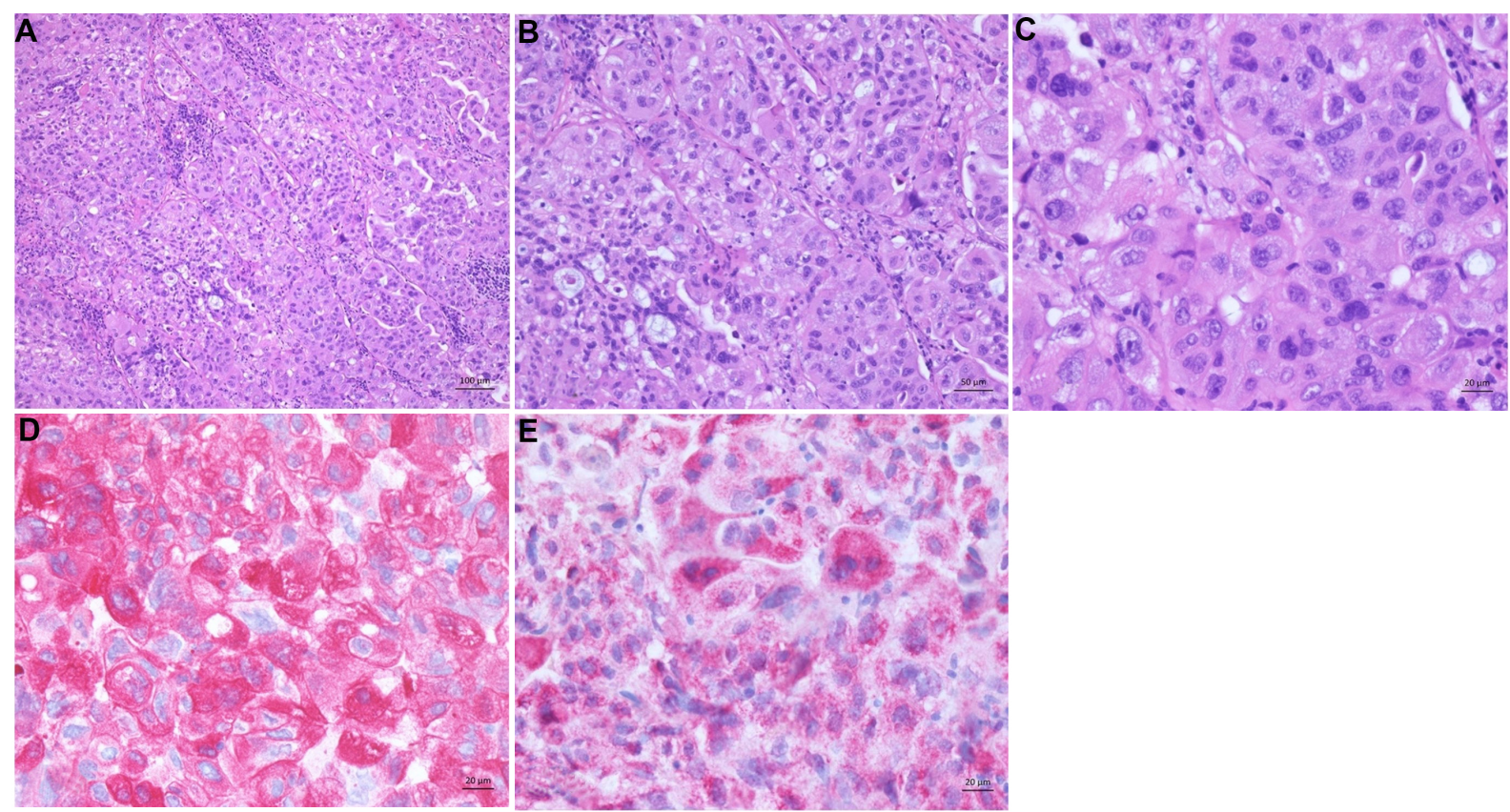

Figure 11. Hepatoid adenocarcinoma. (A) The tumor shows hepatocyte-like tumor cells and lymphoplasmacytic infiltrates localized to stroma and tumor parenchyma. (B) Moderate differentiated tumor cells forming thick trabeculae in the tumor. (C) Hepatocyte-like tumor cells with round nuclei and eosinophilic cytoplasm. (D) Tumor cells are strongly positive for CK7. (E) HepPar1 is also expressed.

and differentiate HCC from metastases of other origins. In this case, the markers thyroid transcription factor 1 (TTF 1) (for lung and thyroid), caudal-type homeobox transcription factor 2 (CDX 2) (for colorectum), GATA binding protein 3 (GATA3) (for breast and urothelium), NK3 homeobox 1 (NKX3.1) (for prostate), paired-box-protein 8 (PAX8) (for gynecological tumors, kidney, and thyroid gland), special AT-rich sequence-binding protein 2 (SATB2) (for enteric differentiation), and SRY-box transcription factor 10 (SOX10) (for melanoma) can be used ${ }^{[0,97]}$. Nevertheless, in almost all cases, this differential diagnosis could be ruled out by using H\&E stains. Molecular markers did not have value until now ${ }^{[65]}$.

\section{CONCLUSION FOR THE CLINIC}

Due to the increasing incidence and the histological variety of HCC, the histopathological diagnosis is essential for diagnosis and therapy of the tumor. Biopsy indications are well established in the diagnostic algorithm of HCC, even in cirrhotic liver. A biopsy should always be used in the palliative situation and when non-invasive methods are unequivocal. Especially if there is any doubt about the diagnosis of HCC, a biopsy should be considered in the first place.

\section{DECLARATIONS}

\section{Authors' contributions}

Made substantial contributions to conception and design of the script: Gisder DM Made substantial contributions to conception and design of the script: Tannapfel A Made substantial contributions to conception and design of the script and selected the case images: Tischoff I

\section{Availability of data and materials}

Not applicable. 


\section{Financial support and sponsorship}

None.

\section{Conflicts of interest}

All authors declared that there are no conflicts of interest.

\section{Ethical approval and consent to participate}

Not applicable.

\section{Consent for publication}

Not applicable.

\section{Copyright}

(c) The Author(s) 2022.

\section{REFERENCES}

1. GCO Global Cancer Observatory. The Global Cancer Observatory (GCO) is an interactive web-based platform presenting global cancer statistics to inform cancer control and research. Available from: https://gco.iarc.fr [Last accessed on $31 \mathrm{Dec} 2021$ ].

2. European Association for the Study of the Liver. Electronic address: easloffice@easloffice.eu, European Association for the Study of the Liver. EASL Clinical Practice Guidelines: Management of hepatocellular carcinoma. J Hepatol 2018;69:182-236. DOI

3. ZfKD Zentrum für Krebsregisterdaten. Das Zentrum für Krebsregisterdaten (ZfKD) am Robert Koch-Institut in Berlin führt Daten der Landeskrebsregister auf Bundesebene zusammen. Available from: http://krebsdaten.de/ [Last accessed on 31 Dec 2021].

4. De Toni EN, Schlesinger-Raab A, Fuchs M, et al. Age independent survival benefit for patients with hepatocellular carcinoma (HCC) without metastases at diagnosis: a population-based study. Gut 2020;69:168-76. DOI PubMed PMC

5. Erhardt A, Theobald I, Petry W, et al. [Hepatocellular carcinoma: rising incidence of hepatitis C virus-associated cases at a university clinic in Germany]. Dtsch Med Wochenschr 2002;127:2665-8. DOI PubMed

6. Zhou L, Liu J, Luo F. Serum tumor markers for detection of hepatocellular carcinoma. World J Gastroenterol 2006;12:1175-81. DOI PubMed PMC

7. Spangenberg HC, Thimme R, Blum HE. Serum markers of hepatocellular carcinoma. Semin Liver Dis 2006;26:385-90. DOI PubMed

8. Nassar A, Cohen C, Siddiqui MT. Utility of glypican-3 and survivin in differentiating hepatocellular carcinoma from benign and preneoplastic hepatic lesions and metastatic carcinomas in liver fine-needle aspiration biopsies. Diagn Cytopathol 2009;37:629-35. DOI PubMed

9. Edmondson HA, Steiner PE. Primary carcinoma of the liver. A study of 100 cases among 48,900 necropsies. Cancer 1954;7:462-503. DOI PubMed

10. Nzeako UC, Goodman ZD, Ishak KG. Hepatocellular carcinoma in cirrhotic and noncirrhotic livers. A clinico-histopathologic study of 804 North American patients. Am J Clin Pathol 1996;105:65-75. DOI PubMed

11. Nzeako UC, Goodman ZD, Ishak KG. Comparison of tumor pathology with duration of survival of north american patients with hepatocellular carcinoma. Cancer 1995;76:579-88. DOI PubMed

12. Paradis VFM. PYSP, tumors of the liver and intrahepatic bile ducts. In: WHO Classification of Tumours Editorial Board WHOClassification of Tumours. 5th ed. Digestive system tumours. International Agency for Research on Cancer; 2019. p. 215-64.

13. Wittekind C. TNM Klassifikation maligner Tumoren: Korrigierter Nachdruck 2020 mit allen Ergänzungen der UICC aus den Jahren 2017 b is 2019. 8th ed. Weinheim: Wiley-VCH; 2020. DOI

14. Bray F, Ferlay J, Laversanne M, et al. Cancer incidence in five continents: inclusion criteria, highlights from volume X and the global status of cancer registration. Int J Cancer 2015;137:2060-71. DOI PubMed

15. Altekruse SF, Henley SJ, Cucinelli JE, McGlynn KA. Changing hepatocellular carcinoma incidence and liver cancer mortality rates in the United States. Am J Gastroenterol 2014;109:542-53. DOI PubMed PMC

16. Horigome H, Nomura T, Saso K, Itoh M, Joh T, Ohara H. Limitations of imaging diagnosis for small hepatocellular carcinoma: comparison with histological findings. J Gastroenterol Hepatol 1999;14:559-65. DOI PubMed

17. Ikai I, Arii S, Kojiro M, et al. Reevaluation of prognostic factors for survival after liver resection in patients with hepatocellular carcinoma in a Japanese nationwide survey. Cancer 2004;101:796-802. DOI PubMed

18. Kojiro M. Focus on dysplastic nodules and early hepatocellular carcinoma: an Eastern point of view. Liver Transpl 2004;10:S3-8. DOI PubMed

19. Krücker J, Xu S, Glossop N, et al. Electromagnetic tracking for thermal ablation and biopsy guidance: clinical evaluation of spatial accuracy. J Vasc Interv Radiol 2007;18:1141-50. DOI PubMed PMC

20. Hakime A, Deschamps F, De Carvalho EG, Barah A, Auperin A, De Baere T. Electromagnetic-tracked biopsy under ultrasound guidance: preliminary results. Cardiovasc Intervent Radiol 2012;35:898-905. DOI PubMed

21. Kang TW, Rhim H. Recent advances in tumor ablation for hepatocellular carcinoma. Liver Cancer 2015;4:176-87. DOI PubMed 
$\mathrm{PMC}$

22. S3-leitlin. Diagnostik und Ther. des Hepatozellulären Karzinoms und biliärer Karzinome. Available from: https://www.leitlinienprogramm-onkologie.de/leitlinien/hcc-und-biliaere-karzinome/ [Last accessed on 19 October 2021].

23. Di Tommaso L, Destro A, Seok JY, et al. The application of markers (HSP70 GPC3 and GS) in liver biopsies is useful for detection of hepatocellular carcinoma. J Hepatol 2009;50:746-54. DOI PubMed

24. Di Tommaso L, Franchi G, Park YN, et al. Diagnostic value of HSP70, glypican 3, and glutamine synthetase in hepatocellular nodules in cirrhosis. Hepatology 2007;45:725-34. DOI PubMed

25. Koehne de Gonzalez AK, Salomao MA, Lagana SM. Current concepts in the immunohistochemical evaluation of liver tumors. World J Hepatol 2015;7:1403-11. DOI PubMed PMC

26. Neuberger J, Patel J, Caldwell H, et al. Guidelines on the use of liver biopsy in clinical practice from the British Society of Gastroenterology, the Royal College of Radiologists and the Royal College of Pathology. Gut 2020;69:1382-403. DOI PubMed PMC

27. Ichim VA, Chira RI, Mircea PA, Nagy GA, Crisan D, Socaciu MA. Accuracy of endoscopic ultrasound-guided biopsy of focal liver lesions. Med Ultrason 2020;22:20-5. DOI PubMed

28. Colloredo G, Guido M, Sonzogni A, Leandro G. Impact of liver biopsy size on histological evaluation of chronic viral hepatitis: the smaller the sample, the milder the disease. J Hepatol 2003;39:239-44. DOI PubMed

29. Bedossa P, Dargère D, Paradis V. Sampling variability of liver fibrosis in chronic hepatitis C. Hepatology 2003;38:1449-57. DOI PubMed

30. Schiano T, Azeem S, Bodian C, et al. Importance of specimen size in accurate needle liver biopsy evaluation of patients with chronic hepatitis C. Clin Gastroenterol Hepatol 2005;3:930-5. DOI PubMed

31. Wyatt J, Hubscher S, Bellamy C. Tissue pathways for liver biopsies for the investigation of medical disease and for focal leasions. The Royal College of Pathologists 2014. DOI

32. Chi H, Hansen BE, Tang WY, et al. Multiple biopsy passes and the risk of complications of percutaneous liver biopsy. Eur $J$ Gastroenterol Hepatol 2017;29:36-41. DOI PubMed

33. Maharaj B, Bhoora IG. Complications associated with percutaneous needle biopsy of the liver when one, two or three specimens are taken. Postgrad Med J 1992;68:964-7. DOI PubMed PMC

34. Perrault J, Mcgill DB, Ott BJ, Taylor WF. Liver biopsy: complications in 1000 inpatients and outpatients. Gastroenterology 1978;74:103-6. PubMed

35. Rockey DC, Caldwell SH, Goodman ZD, Nelson RC, Smith AD; American Association for the Study of Liver Diseases. Liver biopsy. Hepatology 2009;49:1017-44. DOI PubMed

36. Silva MA, Hegab B, Hyde C, Guo B, Buckels JA, Mirza DF. Needle track seeding following biopsy of liver lesions in the diagnosis of hepatocellular cancer: a systematic review and meta-analysis. Gut 2008;57:1592-6. DOI PubMed

37. Müllhaupt B, Durand F, Roskams T, Dutkowski P, Heim M. Is tumor biopsy necessary? Liver Transpl 2011;17 Suppl 2:S14-25. DOI PubMed

38. Fuks D, Cauchy F, Fusco G, Paradis V, Durand F, Belghiti J. Preoperative tumour biopsy does not affect the oncologic course of patients with transplantable HCC. J Hepatol 2014;61:589-93. DOI PubMed

39. Kokudo T, Hasegawa K, Yamamoto S, et al. Surgical treatment of hepatocellular carcinoma associated with hepatic vein tumor thrombosis. J Hepatol 2014;61:583-8. DOI PubMed

40. Lee YH, Hsu CY, Huang YH, et al. Vascular invasion in hepatocellular carcinoma: prevalence, determinants and prognostic impact. $J$ Clin Gastroenterol 2014;48:734-41. DOI PubMed

41. Amitrano L, Guardascione MA, Brancaccio V, et al. Risk factors and clinical presentation of portal vein thrombosis in patients with liver cirrhosis. J Hepatol 2004;40:736-41. DOI PubMed

42. Psutka SP, Boorjian SA, Thompson RH, et al. Clinical and radiographic predictors of the need for inferior vena cava resection during nephrectomy for patients with renal cell carcinoma and caval tumour thrombus. BJU Int 2015;116:388-96. DOI PubMed

43. Aslam Sohaib S, Teh J, Nargund VH, Lumley JS, Hendry WF, Reznek RH. Assessment of tumor invasion of the vena caval wall in renal cell carcinoma cases by magnetic resonance imaging. J Urol 2002;167:1271-5. DOI PubMed

44. Quencer KB, Friedman T, Sheth R, Oklu R. Tumor thrombus: incidence, imaging, prognosis and treatment. Cardiovasc Diagn Ther 2017:7:S165-77. DOI PubMed PMC

45. Yang L, Lin LW, Lin XY, et al. Ultrasound-guided fine needle aspiration biopsy in differential diagnosis of portal vein tumor thrombosis. Hepatobiliary Pancreat Dis Int 2005;4:234-8. PubMed

46. Lukianchenko AB, Medvedeva BM, Karseladze AI, Romanova KA. Morphology classification of liver tumors (comparison of the last and previous WHO classifications 2010 and 2019). Medicinskâ̂ vizualizaciâ 2020;24:138-43. DOI

47. Kim H, Jang M, Park YN. Histopathological variants of hepatocellular carcinomas: an update according to the 5th edition of the WHO classification of digestive system tumors. J Liver Cancer 2020;20:17-24. DOI

48. Nagtegaal ID, Odze RD, Klimstra D, et al; WHO Classification of Tumours Editorial Board. The 2019 WHO classification of tumours of the digestive system. Histopathology 2020;76:182-8. DOI PubMed PMC

49. Kleiner DE, Bedossa P. Liver histology and clinical trials for nonalcoholic steatohepatitis-perspectives from 2 pathologists. Gastroenterology 2015;149:1305-8. DOI PubMed

50. Shimada M, Rikimaru T, Hamatsu T, et al. The role of macroscopic classification in nodular-type hepatocellular carcinoma. Am J Surg 2001;182:177-82. DOI PubMed

51. Eggel H. Über das primäre Carcinom der Leber. Beitr Pathol Anat Allg Pathol 1901;30:506. DOI 
52. Zimmermann A. Hepatocellular carcinoma (Ordinary Hepatocellular Carcinoma). Tumors and tumor-like lesions of the hepatobiliary tract. Cham: Springer International Publishing; 2016. p. 1-38. DOI

53. Yuki K, Hirohashi S, Sakamoto M, Kanai T, Shimosato Y. Growth and spread of hepatocellular carcinoma: a review of 240 consecutive autopsy cases. Cancer 1990;66:2174-9. DOI PubMed

54. Schlageter M, Terracciano LM, D'Angelo S, Sorrentino P. Histopathology of hepatocellular carcinoma. World J Gastroenterol 2014;20:15955-64. DOI PubMed PMC

55. Paradis V. Histopathology of Hepatocellular Carcinoma. In: Vauthey J, Brouquet A, editors. Multidisciplinary treatment of hepatocellular carcinoma. Berlin: Springer Berlin Heidelberg; 2013. p. 21-32. DOI

56. Feo F, Pascale RM. Multifocal hepatocellular carcinoma: intrahepatic metastasis or multicentric carcinogenesis? Ann Transl Med 2015;3:4. DOI PubMed PMC

57. Chianchiano P, Pezhouh MK, Kim A, et al. Distinction of intrahepatic metastasis from multicentric carcinogenesis in multifocal hepatocellular carcinoma using molecular alterations. Hum Pathol 2018;72:127-34. DOI PubMed PMC

58. Furuta M, Ueno M, Fujimoto A, et al. Whole genome sequencing discriminates hepatocellular carcinoma with intrahepatic metastasis from multi-centric tumors. J Hepatol 2017;66:363-73. DOI PubMed

59. Shimada S, Mogushi K, Akiyama Y, et al. Comprehensive molecular and immunological characterization of hepatocellular carcinoma. EBioMedicine 2019;40:457-70. DOI PubMed PMC

60. Kurogi M, Nakashima O, Miyaaki H, Fujimoto M, Kojiro M. Clinicopathological study of scirrhous hepatocellular carcinoma. $J$ Gastroenterol Hepatol 2006;21:1470-7. DOI PubMed

61. Nakashima T, Okuda K, Kojiro M, et al. Pathology of hepatocellular carcinoma in Japan: 232 consecutive cases autopsied in ten years. Cancer 1983;51:863-77. DOI PubMed

62. Yeh CN, Lee WC, Jeng LB, Chen MF. Pedunculated hepatocellular carcinoma: clinicopathologic study of 18 surgically resected cases. World J Surg 2002;26:1133-8. DOI PubMed

63. Bosman FT, Carneiro F, Hruban RH, et al. WHO classification of tumors of digestive system. WHO press; 2010. p. 304.

64. Torbenson MS. Morphologic subtypes of hepatocellular carcinoma. Gastroenterol Clin North Am 2017;46:365-91. DOI PubMed

65. Rastogi A, Maiwall R, Ramakrishna G, et al. Hepatocellular carcinoma: clinicopathologic associations amidst marked phenotypic heterogeneity. Pathol Res Pract 2021;217:153290. DOI PubMed

66. Leong AS, Sormunen RT, Tsui WM, Liew CT. Hep Par 1 and selected antibodies in the immunohistological distinction of hepatocellular carcinoma from cholangiocarcinoma, combined tumours and metastatic carcinoma. Histopathology 1998;33:318-24. DOI PubMed

67. Lin F, Abdallah H, Meschter S. Diagnostic utility of CD10 in differentiating hepatocellular carcinoma from metastatic carcinoma in fine-needle aspiration biopsy (FNAB) of the liver. Diagn Cytopathol 2004;30:92-7. DOI PubMed

68. Shafizadeh N, Ferrell LD, Kakar S. Utility and limitations of glypican-3 expression for the diagnosis of hepatocellular carcinoma at both ends of the differentiation spectrum. Mod Pathol 2008;21:1011-8. DOI PubMed

69. Wee A. Diagnostic utility of immunohistochemistry in hepatocellular carcinoma, its variants and their mimics. Appl Immunohistochem Mol Morphol 2006;14:266-72. DOI PubMed

70. Minervini MI, Demetris AJ, Lee RG, et al. Utilization of hepatocyte-specific antibody in the immunocytochemical evaluation of liver tumors. Mod Pathol 1997;10:686-92. PubMed

71. Liu H, Yang C, Lu W, Zeng Y. Prognostic significance of glypican-3 expression in hepatocellular carcinoma: a meta-analysis. Medicine (Baltimore) 2018;97:e9702. DOI PubMed PMC

72. Salomao M, Siegel A, Lefkowitch JH, et al. Steatohepatitic hepatocellular carcinoma: a novel histologic variant associated with steatohepatitis and metabolic syndrome. Lab Invest 2011;91. DOI

73. Salomao M, Remotti H, Vaughan R, Siegel AB, Lefkowitch JH, Moreira RK. The steatohepatitic variant of hepatocellular carcinoma and its association with underlying steatohepatitis. Hum Pathol 2012;43:737-46. DOI PubMed

74. Salomao M, Yu WM, Brown RS Jr, Emond JC, Lefkowitch JH. Steatohepatitic hepatocellular carcinoma (SH-HCC): a distinctive histological variant of HCC in hepatitis C virus-related cirrhosis with associated NAFLD/NASH. Am J Surg Pathol 2010;34:1630-6. DOI PubMed

75. Yeh MM, Liu Y, Torbenson M. Steatohepatitic variant of hepatocellular carcinoma in the absence of metabolic syndrome or background steatosis: a clinical, pathological, and genetic study. Hum Pathol 2015;46:1769-75. DOI PubMed

76. Bannasch P, Ribback S, Su Q, Mayer D. Clear cell hepatocellular carcinoma: origin, metabolic traits and fate of glycogenotic clear and ground glass cells. Hepatobiliary Pancreat Dis Int 2017;16:570-94. DOI PubMed

77. Liu Z, Ma W, Li H, Li Q. Clinicopathological and prognostic features of primary clear cell carcinoma of the liver. Hepatol Res 2008;38:291-9. DOI PubMed

78. Ji SP, Li Q, Dong H. Therapy and prognostic features of primary clear cell carcinoma of the liver. World J Gastroenterol 2010;16:7649. DOI PubMed PMC

79. Ziol M, Poté N, Amaddeo G, et al. Macrotrabecular-massive hepatocellular carcinoma: a distinctive histological subtype with clinical relevance. Hepatology 2018;68:103-12. DOI PubMed

80. Calderaro J, Couchy G, Imbeaud S, et al. Histological subtypes of hepatocellular carcinoma are related to gene mutations and molecular tumour classification. J Hepatol 2017;67:727-38. DOI PubMed

81. Renne SL, Woo HY, Allegra S, et al. Vessels encapsulating tumor clusters (VETC) is a powerful predictor of aggressive hepatocellular carcinoma. Hepatology 2020;71:183-95. DOI PubMed

82. Lee JH, Choi MS, Gwak GY, et al. Clinicopathologic characteristics and long-term prognosis of scirrhous hepatocellular carcinoma. 
Dig Dis Sci 2012;57:1698-707. DOI PubMed

83. Matsuura S, Aishima S, Taguchi K, et al. 'Scirrhous' type hepatocellular carcinomas: a special reference to expression of cytokeratin 7 and hepatocyte paraffin 1. Histopathology 2005;47:382-90. DOI PubMed

84. Kim YJ, Rhee H, Yoo JE, et al. Tumour epithelial and stromal characteristics of hepatocellular carcinomas with abundant fibrous stroma: fibrolamellar versus scirrhous hepatocellular carcinoma. Histopathology 2017;71:217-26. DOI PubMed

85. Choi SY, Kim YK, Min JH, et al. Added value of ancillary imaging features for differentiating scirrhous hepatocellular carcinoma from intrahepatic cholangiocarcinoma on gadoxetic acid-enhanced MR imaging. Eur Radiol 2018;28:2549-60. DOI PubMed

86. Craig JR, Peters RL, Edmondson HA, Omata M. Fibrolamellar carcinoma of the liver: a tumor of adolescents and young adults with distinctive clinico-pathologic features. Cancer 1980;46:372-9. DOI PubMed

87. Eggert T, McGlynn KA, Duffy A, Manns MP, Greten TF, Altekruse SF. Fibrolamellar hepatocellular carcinoma in the USA, 20002010: a detailed report on frequency, treatment and outcome based on the Surveillance, Epidemiology, and End Results database. United European Gastroenterol J 2013;1:351-7. DOI PubMed PMC

88. Stipa F, Yoon SS, Liau KH, et al. Outcome of patients with fibrolamellar hepatocellular carcinoma. Cancer 2006;106:1331-8. DOI PubMed

89. Kakar S, Burgart LJ, Batts KP, Garcia J, Jain D, Ferrell LD. Clinicopathologic features and survival in fibrolamellar carcinoma: comparison with conventional hepatocellular carcinoma with and without cirrhosis. Mod Pathol 2005;18:1417-23. DOI PubMed

90. Berman MA, Burnham JA, Sheahan DG. Fibrolamellar carcinoma of the liver: an immunohistochemical study of nineteen cases and a review of the literature. Human Pathology 1988;19:784-94. DOI PubMed

91. Ringe B, Wittekind C, Weimann A, et al. Results of hepatic resection and transplantation for fibrolamellar carcinoma. Surg Gynecol Obstet 1992;175:299-305. PubMed

92. Titelbaum DS, Burke DR, Meranze SG, Saul SH. Fibrolamellar hepatocellular carcinoma: pitfalls in nonoperative diagnosis. Radiology 1988;167:25-30. DOI PubMed

93. McLarney JK, Rucker PT, Bender GN, Goodman ZD, Kashitani N, Ros PR. Fibrolamellar carcinoma of the liver: radiologicpathologic correlation. Radiographics 1999;19:453-71. DOI PubMed

94. Edmondson HA. Differential diagnosis of tumors and tumor-like lesions of liver in infancy and childhood. AMA J Dis Child 1956;91:168-86. DOI PubMed

95. Torbenson MS, Yeh MM. Steatohepatitic hepatocellular carcinoma. Hepatoma Res 2021;7:38. DOI

96. Lin F, Liu H. Immunohistochemistry in undifferentiated neoplasm/tumor of uncertain origin. Arch Pathol Lab Med 2014;138:1583610. DOI PubMed

97. Miettinen M, Wang Z, McCue PA, et al. SALL4 expression in germ cell and non-germ cell tumors: a systematic immunohistochemical study of 3215 cases. Am J Surg Pathol 2014;38:410-20. DOI PubMed PMC 